\title{
Peak Voltage Measurements Using Standard Sphere Gap Method
}

\author{
Constantin Ungureanu' ${ }^{1}$ and Lăcrămioara Mihaela Nemţoi ${ }^{2}$ \\ ${ }^{1}$ Department of Electrotechnics, Faculty of Electrical Engineering and Computer Science, 13 University Street, 720229 Suceava, Romania \\ ${ }^{2}$ Department of Telematics and Electronics in Transports, Faculty of Transports, Politehnica University, \\ 313 Splaiul Independentei, Sector 6, 060042 Bucharest, Romania
}

Correspondence should be addressed to Constantin Ungureanu; costel@eed.usv.ro

Received 21 July 2014; Accepted 29 September 2014; Published 8 October 2014

Academic Editor: José R. C. Piqueira

Copyright (c) 2014 C. Ungureanu and L. M. Nemțoi. This is an open access article distributed under the Creative Commons Attribution License, which permits unrestricted use, distribution, and reproduction in any medium, provided the original work is properly cited.

The paper presents a measurement system of peak value of high voltage (H.V.) using $150 \mathrm{~mm}$ diameter sphere gap, disposed in vertical position. Experimental breakdown results have been compared with standard values at atmospheric reference conditions STC $\left(20^{\circ} \mathrm{C}, 101.3 \mathrm{kPa}\right.$, or $\left.760 \mathrm{mmHg}\right)$. The main experimental and theoretical characteristics are presented.

\section{Introduction}

Choosing the most suitable method for measuring high voltage depends on the measured voltage value, on the available measuring devices, and on whether the need is to measure the peak or the effective value. It is known that spark gap spheres measure the peak $\mathrm{AC}$ voltage with a precision of $\pm 3 \%$. The breakdown voltage depends on the distance between the spheres, on the spheres diameter, and on the type of voltage: direct, alternating, or impulse. The breakdown voltage is a nonlinear function of the gap distance which is due to the increasing field inhomogeneity [1]. Sphere gaps can be arranged vertically, with the lower sphere grounded, or horizontally. In both cases, one must take into account the parameters $A$ and $B$ which define the field distribution between the two spheres that are closest to each other. For $150 \mathrm{~mm}$ sphere diameter, the minimum value of $A$ is $6 D$ and the maximum value is $8 D$ (where $D$ is the sphere diameter) while the minimum value for parameter $B$ minimum is $12 S$ (where $S$ is the spacing) [2,3].

Sphere gap can be considered as an approved calibration device, with a limited accuracy, but with high reliability and simplicity [4]. The breakdown field distribution can be controlled by the geometry of the electrode and by the air density. In some cases, the spark gap needs to be irradiated with ultraviolet light or X-rays sources in order to obtain consistent values for smaller sphere gaps, with the gap spacing less than $1 \mathrm{~cm}[3,4]$.
The breakdown voltage of a sphere gap is affected by some factors: atmospheric conditions, nearby earthed objects, voltage ramp-up time, and irradiation which is necessary when the diameter of the sphere gap is less than $10 \mathrm{~cm}$ and measured voltage below $50 \mathrm{kV}$ [3-6]. The breakdown probability depends on the air density and on ion density in the air. Therefore, in the successive breakdown experiments it is necessary to have identical ion densities in the gas gap, before every new voltage application $[7,8]$. The factors that can modify the breakdown voltage have been analyzed in the scientific literature $[4,9,10]$. The breakdown voltage increases with humidity. The increase is about 2-3 percent for normal humidity values between 8 and $15 \mathrm{~g} / \mathrm{m}^{3}$ [4]. For sphere gaps spacing less than one meter the effect of humidity can be ignored [8].

The breakdown voltage depends on the temperature and pressure. Experimental values related to standard conditions (STC) $\left(20^{\circ} \mathrm{C}, 101.3 \mathrm{kPa}\right.$, or $\left.760 \mathrm{mmHg}\right)$ must be multiplied with air the density factor $(\delta)[8,11]$ :

$$
V_{\text {exp. }}=k V_{0} \text {, }
$$

where $V_{\text {exp. }}$ is the breakdown voltage under test conditions, $V_{0}$ is the breakdown voltage at STC, and $k$ is a function of air density factor. 

[11]:

The air density factor is given by the following equation

$$
\delta=\frac{p}{p_{0}} \cdot \frac{273+t_{0}}{273+t}
$$

where $p_{0}$ is the air pressure at standard conditions (760 $\mathrm{mmHg}), p$ is the air pressure at test conditions, $t_{0}$ is the temperature at standard condition $\left(20^{\circ} \mathrm{C}\right)$, and $t$ is the temperature at test conditions. The relation between the correction factor $k$ and the air density factor $\delta$ is known in scientific literature $[3,4,9,11,12]$.

In a nonuniform field the autonomy condition of breakdown may be used. Considering this condition the similarity law of breakdowns can be established: "in a nonuniform field, at constant temperature, the breakdown voltage depends on the $p d$ and on the reports of all other geometric dimensions of the gap and the distance $d "[8,13]$ :

$$
U=f\left(p d, \frac{r_{1}}{d}, \frac{r_{2}}{d}, \ldots\right) .
$$

The scientific literature gives an empirical relationship for the calculation of the breakdown voltage between two identical spheres [8]:

$$
U=27.2 \cdot \delta \cdot r \cdot \frac{(1+0.54 / \sqrt{\delta \cdot r}) \cdot d / r}{0.25\left[d / r+1+\sqrt{(d / r+1)^{2}+8}\right]}
$$

where $d$ is the gap spacing in $\mathrm{cm}, r$ is the radius of the sphere, and $\delta$ is the air density factor.

To measure high voltage with spark gap spheres it is necessary to use a noninductive protection resistance between the source and the sphere gap, in order to limit the breakdown current. The value of the series resistance can vary from $100 \mathrm{k} \Omega$ to $1000 \mathrm{k} \Omega$ for alternating voltages and less than $500 \Omega$ for impulse voltages [3]. The applied voltage is uniformly increased until breakdown occurs in the sphere gap. Usually, a mean of about three breakdown values is taken into account, with an accuracy of $\pm 3 \%$.

\section{Experimental Setup}

For measuring the peak values we used experimental spark gap spheres, in vertical arrangement. Two metal spheres of equal diameters, with smooth surfaces and uniform curvature, were used in the experiment. The upper sphere is connected to a $0-180 \mathrm{kV}$ high voltage AC power source through a noninductive resistor of $100 \mathrm{k} \Omega$. The bottom sphere is connected to the ground with the possibility of vertical position changing towards the upper sphere by a DC electrical engine.

The distance between the spheres with $150 \mathrm{~mm}$ in diameter was modified in steps of $0.5 \mathrm{~cm}$ from $1 \mathrm{~cm}$ to $6 \mathrm{~cm}$. The block diagram of the experimental test bench is presented in Figure 1. To measure the breakdown voltage, a high voltage probe (Hameg probe) with $1000: 1$ voltage division ratio and a multimeter (Meterman 38XR) was used. The high voltage probe was connected to a Tektronix TDS $2024 \mathrm{C}(200 \mathrm{MHz}$,

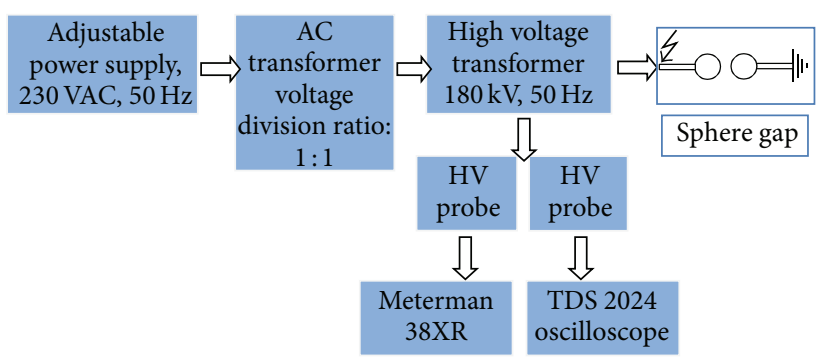

FIGURE 1: Block diagram of the test bench.

$2 \mathrm{GS} / \mathrm{s}$ ) oscilloscope, to view the shape of the breakdown voltage waveform. The temperature and relative humidity have been measured with a Lutron LM-8000 meter with the following specifications: relative humidity between 10 and $95 \% \mathrm{RH}(0,1 \% \mathrm{RH}$ accuracy) and temperature between 0 and $50^{\circ} \mathrm{C}\left(0,1^{\circ} \mathrm{C}\right.$ accuracy). The block diagram of the test bench is presented in Figure 1.

The arrangement for the construction of the sphere gap is shown in Figure 2, where parameters $A$ and $B$ are defined. The sparking point which is established by parameter $A$ must be within given limits related to the sphere diameter $D$, $6 D \leq A \leq 8 D$ [11]. In order to be considered as a standard measuring device, a minimum value for $B(B \geq 12 d)$ around the sphere must be available. Also, the surfaces of the sphere near the sparking point should be free of irregularities or grease.

2.1. Test Conditions. All the experiments were carried out at room temperature $19^{\circ} \mathrm{C}$, air pressure $760.56 \mathrm{mmHg}$, absolute humidity $8.13 \mathrm{~g} / \mathrm{m}^{3}$, and $50 \%$ relative humidity. For a given distance between the spheres, three successive measurements were made. The final value of the breakdown voltage was determined as the average of five successive measurements, with an error of less than $3 \%$.

Various studies have been made over the time concerning the time gap between two consecutive breakdowns $[14,15]$. For the scope of the present work this time gap has been set to at least one minute.

The experimental test setup presented below (Figure 3 ) is used to measure the AC high voltage, $50 \mathrm{~Hz}$, applied to the sphere gap. The breakdown voltage is measured by modifying the gap spacing from $1 \mathrm{~cm}$ up to $6 \mathrm{~cm}$, according to the available standards [11]. All the components of the spark gap spheres were made of insulating materials.

\section{Results}

The standard peak values of breakdown voltage $\left(\mathrm{kV}_{\max }\right)$, in air, for symmetrical spheres of $150 \mathrm{~mm}$ in diameter, have been corrected to the standard temperature and pressure according to relations (1) and (2). The experimental data are listed in Table 1. Corrections were made for standard peak values at STC, according to recommended standards. The relative humidity has not been considered. The breakdown voltages measured at test conditions are close to the standard peak values. The errors between the measured breakdown voltages 
TABLE 1: Breakdown voltage data.

\begin{tabular}{|c|c|c|c|c|}
\hline \multirow[b]{2}{*}{$\begin{array}{l}\text { Distance } \\
d[\mathrm{~cm}]\end{array}$} & \multicolumn{4}{|c|}{ Test conditions: $19^{\circ} \mathrm{C} ; 760.56 \mathrm{mmHg} ; 8.13 \mathrm{~g} / \mathrm{m}^{3}$} \\
\hline & $\begin{array}{c}\text { Experimental breakdown } \\
\text { voltage } \\
U_{\text {exp. }}\left[\mathrm{kV}_{\max }\right]\end{array}$ & $\begin{array}{c}\text { Standard peak values at } \\
\text { STC } \\
U_{0}\left[\mathrm{kV}_{\max }\right]\end{array}$ & $\begin{array}{l}\text { Theoretical values } \\
U_{t}\left[\mathrm{kV}_{\max }\right]\end{array}$ & $\begin{array}{l}\text { Standard peak values [2] } \\
\qquad U_{0}\left[\mathrm{kV}_{\max }\right]\end{array}$ \\
\hline 1 & 31.02 & 31.19 & 31.16 & 31.10 \\
\hline 1.5 & 46.53 & 45.64 & 45.73 & 45.50 \\
\hline 2 & 59.22 & 59.38 & 59.67 & 59.20 \\
\hline 2.5 & 71.06 & 73.12 & 73.01 & 72.90 \\
\hline 3 & 83.24 & 86.06 & 85.77 & 85.80 \\
\hline 3.5 & 94.97 & 98.70 & 97.98 & 98.40 \\
\hline 4 & 106.10 & 111.33 & 109.67 & 111 \\
\hline 4.5 & 119.62 & 123.37 & 120.86 & 123 \\
\hline 5 & 131.97 & 134.40 & 131.58 & 134 \\
\hline 5.5 & 140.79 & 145.44 & 141.84 & 145 \\
\hline 6 & 148.89 & 155.47 & 151.67 & 155 \\
\hline
\end{tabular}

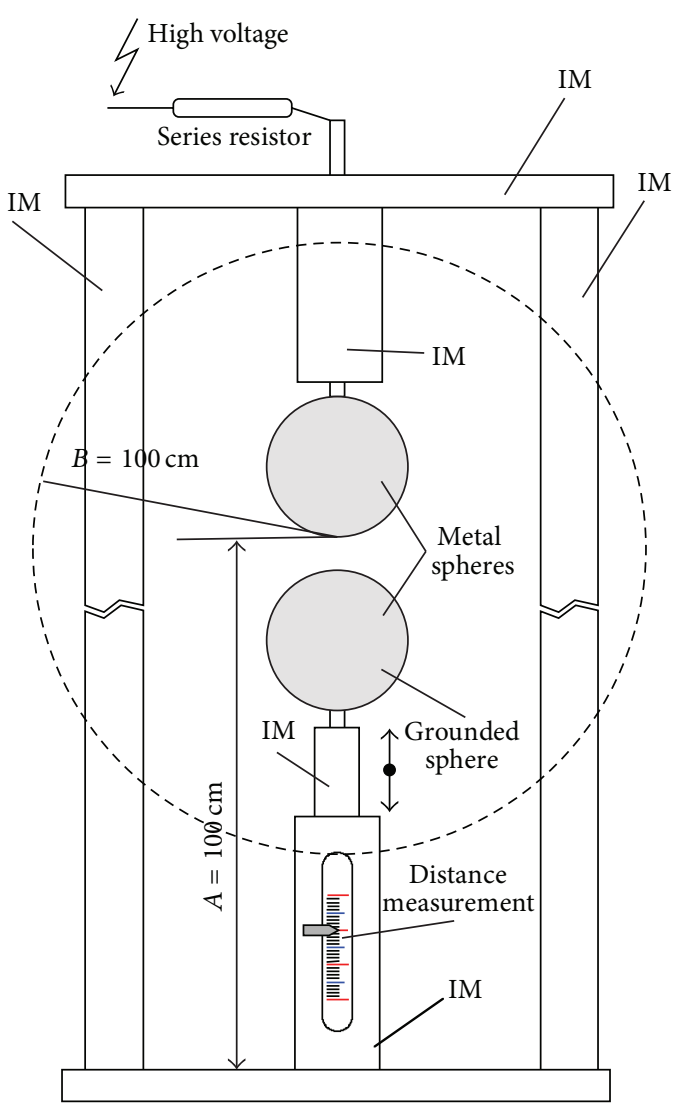

FIGURE 2: Vertical sphere gap: IM: insulating material; $A$, $B$ : clearances parameters; $d$ : gap length; $D$ : sphere diameter $(150 \mathrm{~mm})$.

and the standard ones are less than 3\%, except for those measured at 4 and $6 \mathrm{~cm}$.

Figure 4 shows the variation of measured breakdown voltages and standard peak voltages at STC, as a function of gap spacing. For comparison, Figure 4 represents also the theoretical breakdown voltages obtained through (4), as

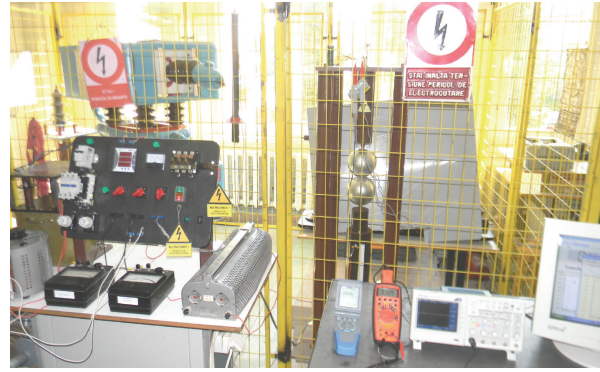

Figure 3: Experimental test setup.

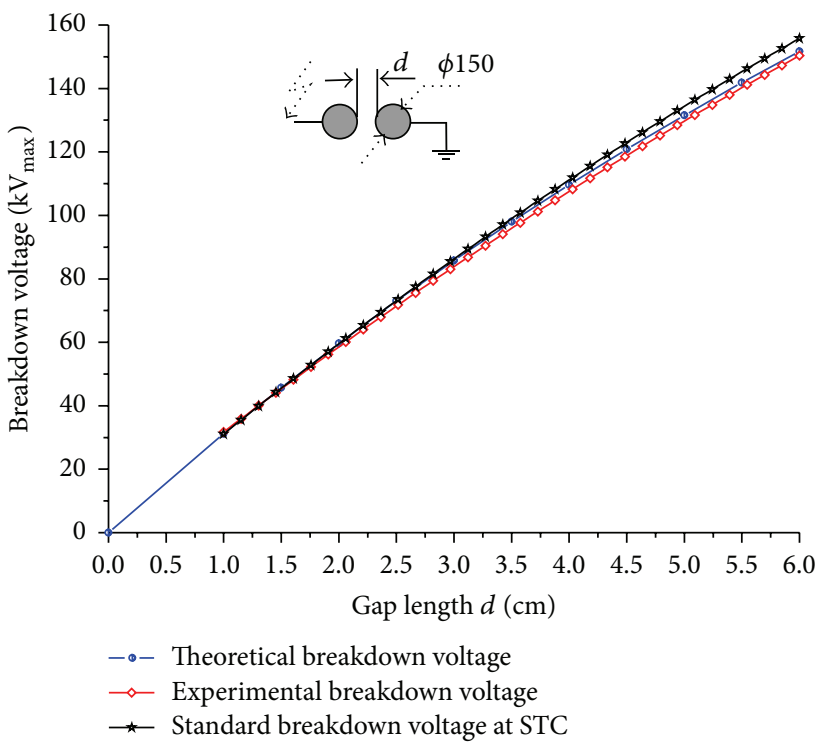

FIGURE 4: Breakdown voltage curves for sphere-sphere electrodes in atmospheric air (at STC and test conditions) with gap length of $1 \mathrm{~cm}$ up $6 \mathrm{~cm}$, for AC voltage, $50 \mathrm{~Hz}$. 
TABLE 2: Comparison between breakdown voltages of uniform field gaps and sphere gaps for shorter distances.

Standard conditions: $20^{\circ} \mathrm{C} ; 760.56 \mathrm{mmHg}$

\begin{tabular}{|c|c|c|c|c|}
\hline \multirow[t]{2}{*}{$\begin{array}{l}\text { Distance } \\
d[\mathrm{~cm}]\end{array}$} & \multicolumn{2}{|c|}{$\begin{array}{l}\text { Breakdown voltage with uniform field electrodes } \\
\text { (proposed sphere gap geometry), measured by }\end{array}$} & \multirow{2}{*}{$\begin{array}{l}\text { Sphere gap breakdown voltage } \\
{[3]\left[\mathrm{kV}_{\max }\right]}\end{array}$} & \multirow{2}{*}{$\begin{array}{l}\text { Experimental breakdown } \\
\text { voltage } U_{\text {exp. }}\left[\mathrm{kV}_{\max }\right]\end{array}$} \\
\hline & Ritz [3] $\left[\mathrm{kV}_{\max }\right]$ & Schumann [3] $\left[\mathrm{kV}_{\max }\right]$ & & \\
\hline 0.1 & 4.54 & 4.50 & 4.60 & - \\
\hline 0.2 & 7.90 & 8.00 & 8.00 & - \\
\hline 0.5 & 17.00 & 17.40 & 17.00 & - \\
\hline 1.0 & 31.35 & 31.70 & 31.00 & 31.02 \\
\hline 2.0 & 58.70 & 59.60 & 58.00 & 59.22 \\
\hline 4.0 & 112.00 & 114.00 & 112.00 & 106.10 \\
\hline 6.0 & 163.80 & 166.20 & 164.00 & 148.89 \\
\hline
\end{tabular}

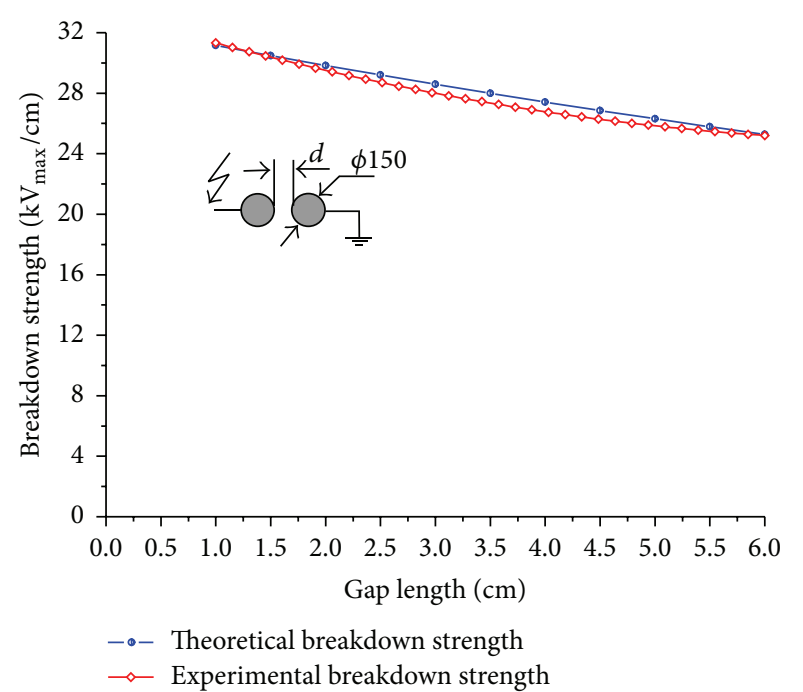

FIGURE 5: Breakdown strength $\left(\mathrm{kV}_{\max } / \mathrm{cm}\right)$ distribution between two spheres of equal radii for different gap spacing in atmospheric air.

a function of gap spacing. The maximum difference between $U_{\text {exp. }}$ and $U_{t}$ is less than $1 \%$. The variation of breakdown strength, in $\mathrm{kV}_{\max } / \mathrm{cm}$, for different gap spacing in atmospheric air at constant pressure, is presented in Figure 5.

Sphere gaps are used for voltage measurements and have only limited range with uniform electric field. In this respect, Rogowski proposed a design for uniform field electrodes for breakdown voltages up to $600 \mathrm{kV}$. It is known that it is not possible to ensure that the sparking always takes place along the uniform field region [3]. In scientific literature are presented breakdown voltage data for uniform fields. Table 2 gives a comparison between the breakdown voltages at STC of a uniform field electrode gap (measured by Ritz and Schumann) a sphere gap [3], and the values obtained in this work.

From the data in Table 2 we can observe that there is no major difference between the breakdown voltages of sphere gaps and the uniform field gaps, at least at small distances between spheres.
The values obtained for the proposed sphere gap (Figure 2) are approaching the ones measured by Ritz and Schumann with specific errors, possibly related to rise time of voltage waveforms, electrodes shape and material, and so forth.

\section{Conclusions}

The breakdown voltages in air, at constant pressure, in nonuniform field, have been measured for AC high voltage, for different gap values between the spheres. It has been shown that the breakdown voltage increases with the gap spacing almost linearly. The accuracy of experimentally determined breakdown voltages has been verified and compared with theoretical values listed in the standards.

The numerical values of experimental breakdown voltages for the $4 \mathrm{~cm}$ and $6 \mathrm{~cm}$ gap spacing show an error above $3 \%$, compared to the values specified in standards. These errors can be attributed to the nonuniform field, which increases as the distance between the spheres is increased.

\section{Conflict of Interests}

The authors declare that there is no conflict of interests regarding the publication of this paper.

\section{References}

[1] B. R. Shreedevi and T. C. Balachandra, "Breakdown behaviour of sub-millimetre air gaps under alternating voltage," in Proceedings of the IEEE 1st International Conference on Condition Assessment Techniques in Electrical Systems (CATCON '13), pp. 88-93, December 2013.

[2] N. K. Kishore, G. S. Punekar, and H. S. Y. Shastry, "Affect of height of HV sphere above the ground in HV measuring sphere gap," in Proceedings of the Conference on Electrical Insulation and Dielectric Phenomena (CEIDP '07), pp. 755-758, October 2007.

[3] M. S. Naidu and V. Kamaraju, High Voltage Enginnering, Tata McGraw-Hill, 2004.

[4] E. Kuffel, W. S. Zaengl, and J. Kuffel, High Voltage Engineering. Fundamentals, Butterworth-Heinemann, 2nd edition, 2000.

[5] N. K. Kishore, G. S. Punekar, and H. S. Y. Shastry, "Sparkover in sphere gaps with alternating voltages and perturbed electric 
fields," in Proceedings of the Annual Report Conference on Electrical Insulation and Dielectric Phenomena (CEIDP '09), pp. 634-637, October 2009.

[6] P. Florentin, "Sampling system for accurate peak voltage measurements," IEEE Transactions on Instrumentation and Measurement, vol. 47, no. 5, pp. 1307-1310, 1998.

[7] G. S. Punekar, V. Mishra, N. K. Kishore, and H. S. Y. Shastry, "Electric fields in the transition region of sphere-gaps to parallel-plane gaps," in Proceedings of the IEEE INDICON 1st India Annual Conference, pp. 460-463, December 2004.

[8] L. I. Sirotinski, High Voltage Technique, Editura Energetica de Stat, 1954.

[9] M. G. Hoog, I. V. Timoshkin, S. J. Macgregor, M. P. Wilson, M. J. Given, and T. Wang, "Breakdown of short gaps at atmospheric pressure," in Proceedings of the IEEE International Conference on Plasma Science (ICOPS '13), p. 1, IEEE, San Francisco, Calif, USA, June 2013.

[10] D. Wu, A. Gunnar, B. Jacobson, M. Li, and F. Sahlen, "Humidity influence on switching-impulse breakdown voltage of air gaps for indoor high-voltage installations," in Proceedings of the 14th International Symposium on High Voltage Engineering Tsinghua University, Beijing, China, August 2005.

[11] The Institute of Electrical and Electronics Engineers, IEEE Standard Techniques for High Voltage Testing, The Institute of Electrical and Electronics Engineers, 1978.

[12] M. G. Hogg, I. V. Timoshkin, S. J. Macgregor, M. P. Wilson, M. J. Given, and T. Wang, "Electrical breakdown of short nonuniform air gaps," in Proceedings of the 19th IEEE Pulsed Power Conference (PPC '13), pp. 1-4, San Francisco, Calif, USA, June 2013.

[13] J. H. Cloete and J. van der Merwe, "The breakdown electric field between two conducting spheres by the method of images," IEEE Transactions on Education, vol. 41, no. 2, pp. 141-145, 1998.

[14] M. Koch, U. Straumann, and C. M. Franck, "Determination of waiting times between successive breakdown experiments," in Proceedings of the IEEE Conference on Electrical Insulation and Dielectric Phenomena (CEIDP '12), pp. 349-352, Montreal, Canada, October 2012.

[15] M. Rezouga, A. Tilmatine, R. Ouiddir, and K. Medles, "Experimental modelling of the breakdown voltage of air using design of experiments," Advances in Electrical and Computer Engineering, vol. 9, no. 1, pp. 41-45, 2009. 

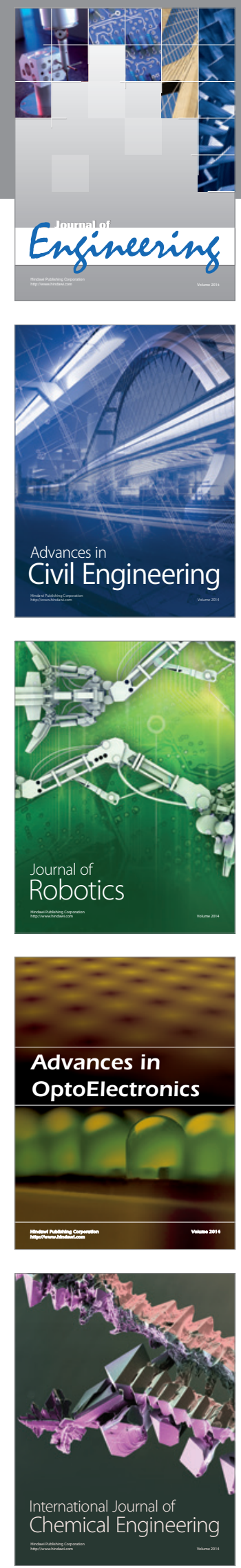

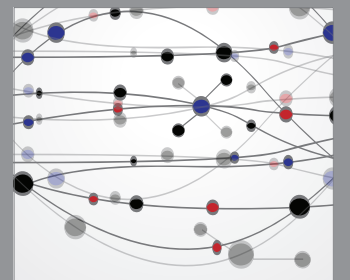

The Scientific World Journal
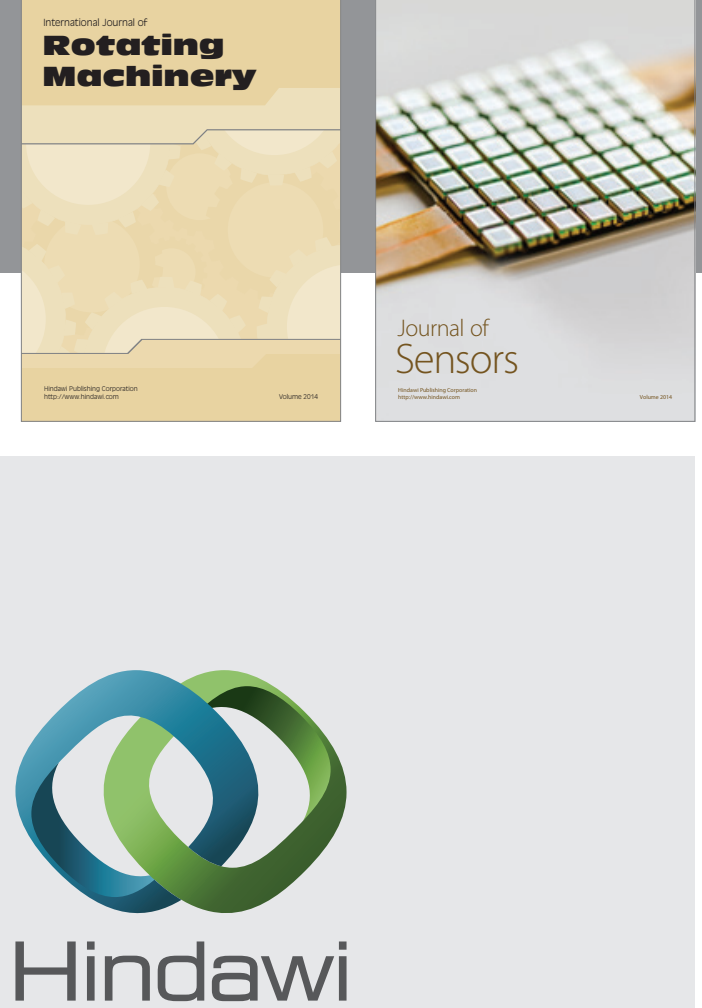

Submit your manuscripts at http://www.hindawi.com
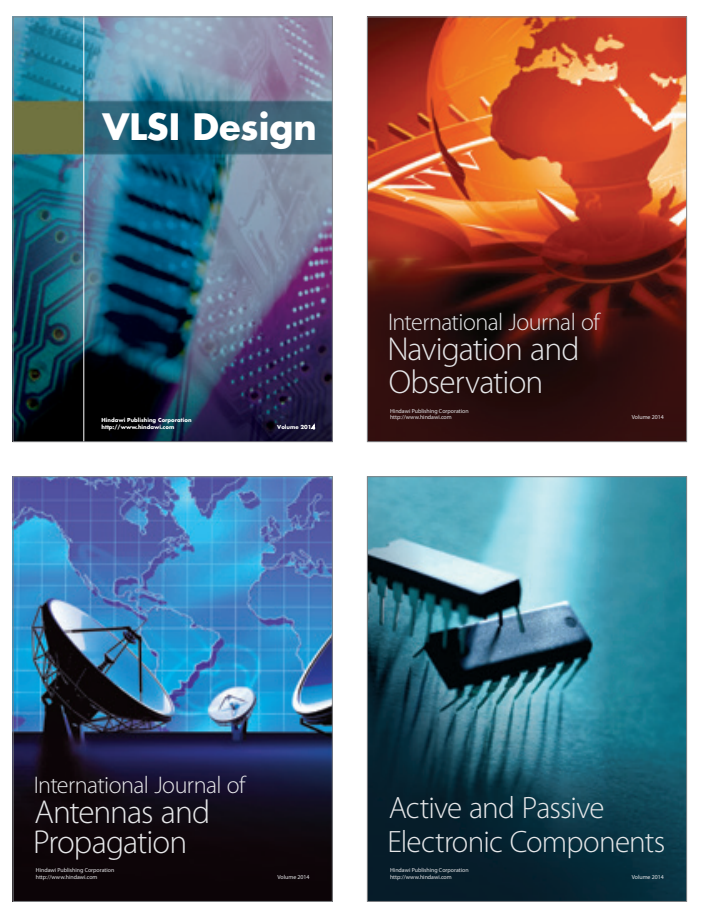
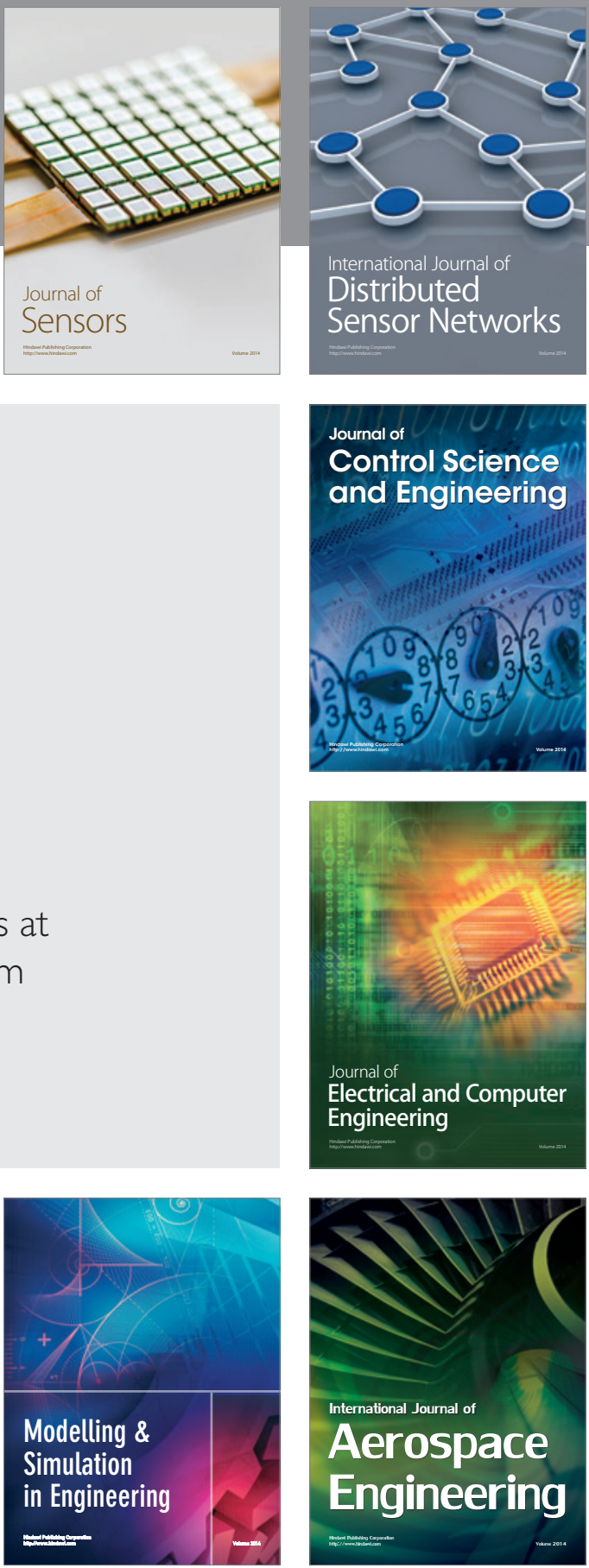

Journal of

Control Science

and Engineering
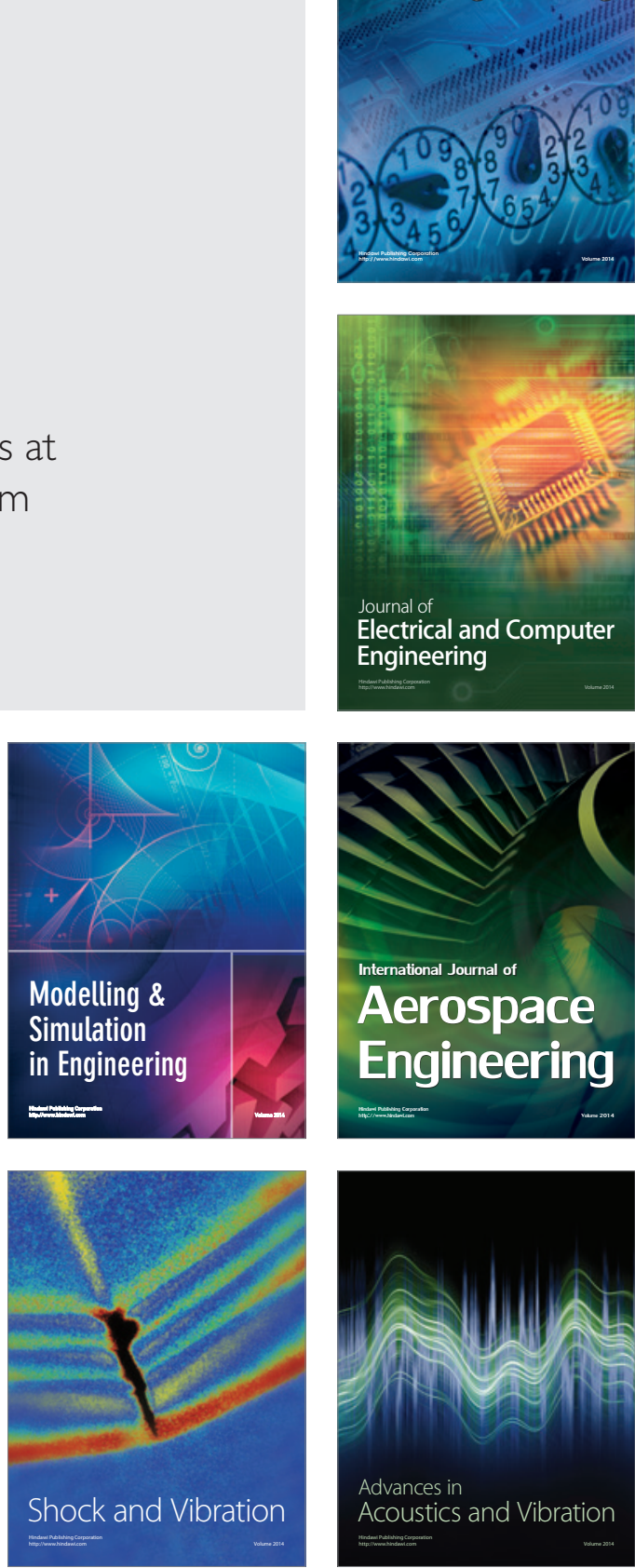